\title{
Special Issue on Metabolic Plant Biology
}

\author{
De-Yu Xie • Anastasios Melis
}

Received: 13 June 2012/ Accepted: 22 June 2012/Published online: 12 July 2012

(C) Springer-Verlag 2012

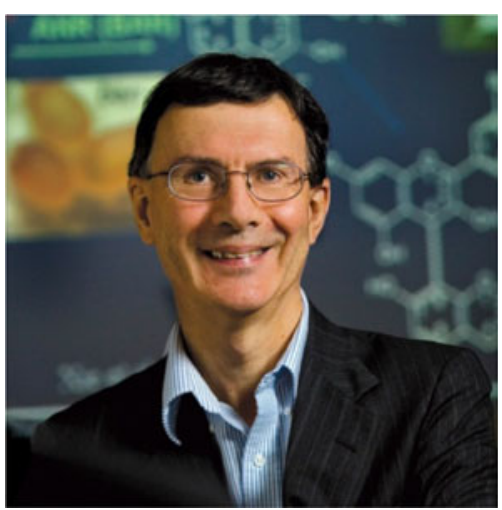

The Special Issue of Planta on Metabolic Plant Biology is dedicated to Professor Richard Arthur Dixon of the Samuel Roberts Noble Foundation on the occasion of his sixtieth birthday. The issue features 15 research contributions from Dr. Dixon's former postdoctoral associates, students, colleagues and collaborators. This Special Issue of Planta affords recognition and appreciation of Dr. Dixon's numerous contributions to the fields of Plant Biology and Metabolism.

Richard A. Dixon is currently Distinguished Professor and Samuel Roberts Noble Research Chair, Senior Vice President and Director of the Plant Biology Division at the

A contribution to the Special Issue on Metabolic Plant Biology.

\section{D.-Y. Xie $(\bowtie)$}

Department of Plant Biology, North Carolina State University,

Raleigh, USA

e-mail: dxie@ncsu.edu

\section{A. Melis}

Department of Plant and Microbial Biology,

University of California, Berkeley, USA
Samuel Roberts Noble Foundation in Ardmore, Oklahoma. $\mathrm{He}$ is a Member of the US National Academy of Sciences and a Fellow of the American Association for the Advancement of Science. The Institute for Scientific Information named him as one of the 10 most cited authors in the plant and animal sciences. The University of Oxford awarded him a Doctor of Science degree in recognition of his numerous research achievements and contributions to the field of plant secondary metabolism. The Oklahoma Academy of Sciences named him "Oklahoma Scientist of the Year", and he was the recipient of the Richard R. Hill Achievement Award for Outstanding Contributions to Alfalfa Research, presented by the National Alfalfa Improvement Congress. Science magazine named him a "Top Principal Investigator" in a 2004 article. The Chamber of Commerce of his hometown in Oklahoma named him "Ardmore Star". He is the 2012 recipient of the Scientific Prize from the Group Polyphenols, and the 2012 Shang-Fa Yang Memorial Lecturer (Taiwan). He has served eleven different plant science journals as editorial board member, associate editor, or editor-in-chief. Furthermore, he has provided service to numerous other academic and industrial organizations.

Rick Dixon's family originates in the UK, although he was born in Cape Town, South Africa on 29 December 1951. His family returned to England when he was just 3 months old. He completed his primary and secondary education in the UK. He earned his Bachelor of Science Degree in Biochemistry from Oxford University in 1973, and his Doctor of Philosophy in Botany from the same university in 1976 at the age of 25. During his Ph.D. studies, conducted under the guidance of Professor Keith Fuller, he investigated the regulation of phaseollin biosynthesis (a phytoalexin metabolite) in cultured cells of Phaseolus vulgaris L. From 1976 to 1978, he served as a 
postdoctoral research fellow in the laboratory of Professor Derek Bendall, Department of Biochemistry, University of Cambridge, UK, where he continued his studies on phytoalexin induction and where he initiated a highly productive collaboration with Chris Lamb, a close friend and colleague. In 1978, he started his independent academic career as a faculty member in the Department of Biochemistry at the Royal Holloway College, University of London.

In 1988, he transitioned to the US, becoming the founding director of the Plant Biology Division at the Noble Foundation. Under his leadership, the Plant Biology Division has grown into a world-famous plant science center with more than 100 scientists and staff. The current focal points of the Division's research include understanding of plant processes at the chemical, molecular and genetic levels, and efforts to accelerate developments in the areas of plant quality, sustainability and bioenergy.

Professor Dixon is a recognized leader in the field of Plant Secondary Metabolism. His research interests center on biochemistry, molecular biology and metabolic engineering of plant natural product pathways (particularly phenylpropanoids) and their implications for agriculture. $\mathrm{He}$ has authored over 400 research papers and book chapters in peer-reviewed journals and currently holds 17 issued patents. Since the start of his scientific career, he has given close to 300 presentations at international scientific conferences, academic institutions, and private sector organizations. Many breakthroughs have been made in his laboratory, including major advances in our understanding of the biosynthesis of lignin, isoflavonoids and condensed tannins. One of his current research passions is the biosynthetic pathways of phenylpropanoids and the possibility of their manipulation to benefit current efforts in the development of dedicated bioenergy crops. Many of his laboratory's findings have become mainstream entries in textbooks and reference manuals, thereby helping students to acquire knowledge and develop a strong appreciation of Metabolic Plant Biology.

A prolific and successful research effort requires the training and mentoring of students, associates, and postdoctoral scholars. In this capacity, Professor Dixon has mentored over 90 postdoctoral fellows and research students, many of who now hold leading positions in academia and in the private sector throughout the world.

On the occasion of his sixtieth birthday, it is our pleasure to dedicate to Professor Dixon this Planta Special Issue on Metabolic Plant Biology. We also take advantage of this opportunity to express our best wishes to Rick for happiness, good health, and continued success in the future. 